\title{
Experimental measurements of flood-induced impact forces on exposed elements
}

\author{
Michael Sturm ${ }^{1, *}$, Bernhard Gems ${ }^{1}$, Florian Keller ${ }^{2}$, Bruno Mazzorana ${ }^{3,4,5}$, \\ Sven Fuchs ${ }^{6}$, Maria Papathoma-Köhle ${ }^{6}$, and Markus Aufleger ${ }^{1}$ \\ ${ }^{1}$ Unit of Hydraulic Engineering, University of Innsbruck, 6020 Innsbruck, Austria \\ ${ }^{2}$ Ingenieurbüro Thomas Haug, 6600 Lechaschau, Austria \\ ${ }^{3}$ Institute of Earth Sciences, Universidad Austral de Chile, 5090000 Valdivia, Chile \\ ${ }^{4}$ Millennium Nucleus CYCLO - The Seismic Cycle Along Subduction Zones, Valdivia, Chile \\ ${ }^{5}$ Research Centre for Assessment and Mitigation of Natural and Anthropogenic Risks (RiNA), \\ Universidad Austral de Chile, 5090000 Valdivia, Chile \\ ${ }^{6}$ Institute of Mountain Risk Engineering, University of Natural Resources and Life Sciences, 1180 \\ Vienna, Austria
}

\begin{abstract}
Torrential flood hazards are a major threat for inhabited alluvial fans. They have the potential to relocate large amounts of sediment from the upper catchments to settlement areas on the alluvial fans where typically distributary processes take place. The approaching water-sediment-mixture impacting on building walls are part of a set of damage-generating mechanisms and may cause severe damages to buildings and infrastructure. It is difficult to predict the magnitude and temporal forces on buildings due to the complex flow patterns and sediment deposition processes around obstacles on the floodplain. Our work focuses on experimental measurements of impact forces of flood events on buildings at a 1:30 scale model. It covers the alluvial fan of the Schnannerbach torrent (Austria) with a set of building structures which are equipped with force measurement devices. The measured impact forces are correlated to the approaching flow heights. Influencing factors on the impacts forces such as surrounding buildings on the floodplain and the presence of openings in the building envelope are also analysed. The influence of different hydraulic flow patterns on the impact forces and regression analyses for an estimation of impact forces are presented.
\end{abstract}

\section{Introduction}

Heavy rainfall events and the mobilization of a substantial volume of sediments often result into hazardous torrential floods in mountainous areas. Limited channel and sediment transport capacities of the affected torrents lead to overtopping of the flow mixture and overbank sedimentation, especially on flat and unconfined alluvial fans in the lower reach of the torrents. Consequences are severe damages of the buildings and infrastructure located on the settled floodplain $[9,11]$. These damages during torrential hazard events are caused by different processes, such as abrasion, scouring, undermining or structural failure due to the

\footnotetext{
*Corresponding author: michael.sturm@uibk.ac.at
} 
impact forces itself. The latter can be divided in impacts of single boulders on the buildings and static and dynamic forces of the approaching flow processes. In particular, when there is a significant amount of sediment transport in the flow, the complex flow processes are difficult to estimate or almost impossible to capture in nature. Recent research mainly focuses on debris flow impacts with high sediment concentrations on single wall elements [12], but the impact forces of fluvial sediment transport on the whole structural envelope of buildings are widely unknown. The impact force itself is difficult to measure during a flood event. With regard to vulnerability analysis of a flood event, indicators such as the approaching flow heights at a building are used to correlate with the damages and economic losses [9].

Scale models provide the opportunity to obtain measurement data of impact forces for different approaching flow heights. With relatively low effort, adjustments of the scale model layout as well as variations of several boundary conditions can be accomplished to test the influences of these parameters on the impact forces. Further, modelling the hazardous process and the impact forces on the building walls may contribute to a better understanding of the interaction between buildings and natural processes which is essential for vulnerability analyses.

In this paper the focus is set on scale model measurements of impact forces induced by fluviatile flood events on building structures located on an alluvial fan. We specifically consider the case study of the Schnannerbach torrent $[2,3,11]$. The case study was chosen because it suffered extended damages during the August 2005 floods which affected Austria and neighbouring countries. The event was very well documented in terms of the natural process itself but also the damages on individual buildings [11]. We anticipate here that this study complements a detailed experimental analysis $[6,15,16]$ and presents also some new data analyses and findings. The different variations of the experiments are summarized and compared with experimental sets. Particular emphasis is devoted to the correlation between the approaching flow heights and the impact forces. Additionally, we explore another relevant influencing factor, the existence of surrounding buildings. Further, different flow and sediment deposition patterns in close range of the obstacle in the flow, which also exert an altering effect on the impact forces, are discussed in more detail.

Preliminary small scale experiments on the impacts on single wall elements in a straight rectangular flume under different boundary conditions are described in $[4,13,14]$ and detailed information of the 2D-numerical reconstruction of the experiments at the Schnannerbach scale model can be found in [15]. The experimental results for the Schnannerbach torrent are compared to those obtained in the aforementioned preliminary studies.

\section{Methods}

The core of our work is a physical scale model based on the torrent channel of Schnannerbach (Austria) [15] and the existing buildings of the floodplain, scaled 1:30 by Froude similarity (Fig. 1). Three of the existing buildings were accurately modelled and measurement devices were installed on 16 wall elements to detect the three-dimensional impact forces with high accuracy and a resolution of $200 \mathrm{~Hz}$. Additional buildings without measurement devices were also accurately modelled and positioned later (light blue buildings in Fig. 1) to investigate the influence of surrounding structures on the impact forces on buildings. Different flood discharges and the corresponding sediment supply can be regulated in order to provide welldefined and precise steady state inflow conditions to the model. 


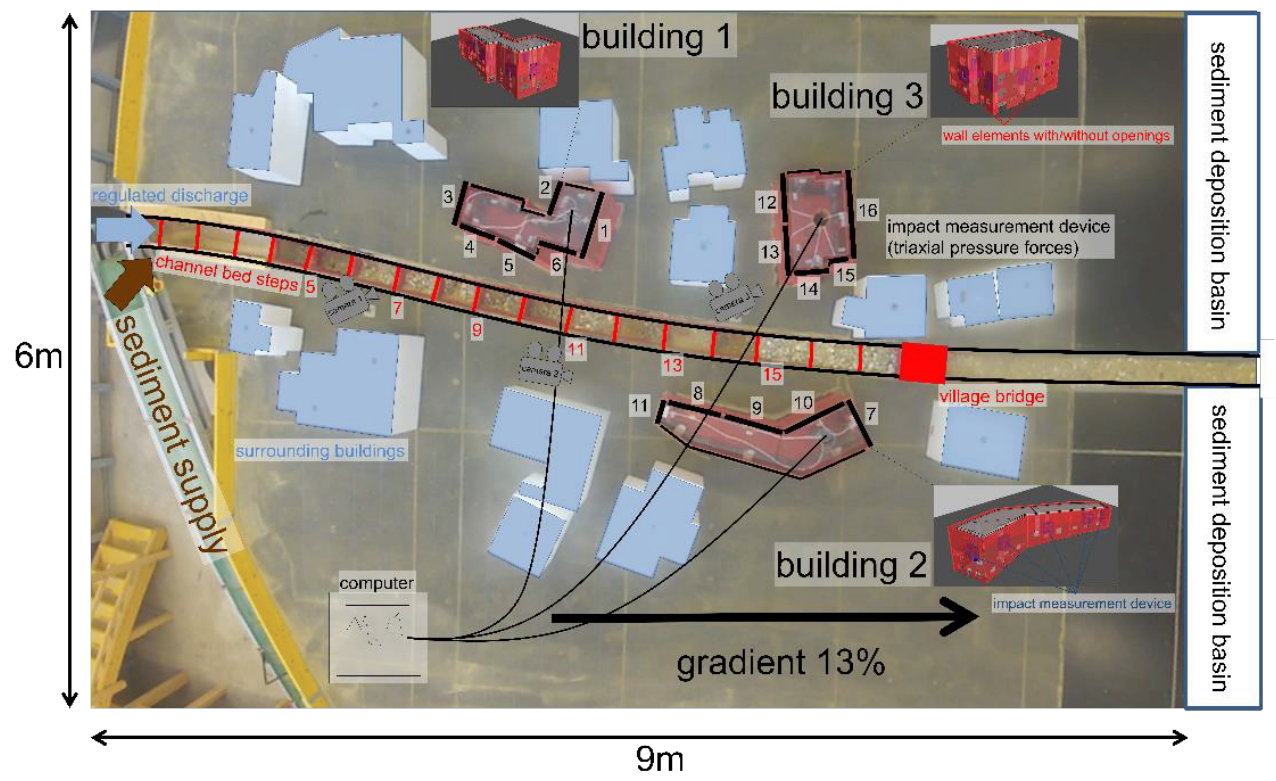

Fig. 1. Main components of the Schnannerbach scale model from top view [13].

The conducted experiments mainly covered tests with clear water conditions and with continuous sediment supply. Further, the experimental programme comprised simulations under different variations of the boundary conditions and model layouts. Therefore, discharges, sediment grain sizes and sediment concentrations were varied for the experiments as well as model layouts considering the influence of surrounding buildings on the floodplain and openings in the building envelope. Within the experiments, flood conditions comparable to those during the destructive flood event in August $2005[2,3,11]$ were simulated. As observed during the flood event, the insufficient bed-load transport capacity and the regressive sediment deposition in the torrent channel caused channel outbursts and led to impacts on the buildings as well as to material intrusion [17]. The specific event and the characteristics of the flow could be reproduced in the experiments. Additionally, the experimental programme covered 120 clear water and 20 sediment experiments [15]. Beside the impact forces, the approaching flow heights at the walls and the flow velocities on the floodplain were considered as important parameters. Accordingly, they were also measured during the experiments.

To systematically induce the required overtopping of the torrent channel, barriers were set at the different locations of the channel bed steps in the channel (clear water) and regressive sediment deposition in the channel caused by insufficient bed-load transport capacity was simulated (sediment loaded conditions). These methods provide appropriate overland flow on the floodplain and streaming flows impacting the wall elements of the buildings to detect the occurring forces.

The experiments were compared to preliminary studies on a simple model setup at 1:30 scale, consisting of a straight rectangular flume and an attached single wall element equipped with the same type of measurement device to detect the impact forces of the flow on a single wall [13]. Different settings of the boundary conditions combined with different model layouts were tested $[4,13,14]$. Comparing the measurements to the Schnannerbach scale model experiments, the measurements of a set of clear water experiments in the flume are illustrated under different flow conditions. These were accomplished through variations of discharge and longitudinal gradient in the flume. Detailed information about the model setup and the whole experimental programme can be found in $[14,15]$. The experimental 
measurements were coupled to numerical models (Flow-3D; BASEMENT) to reconstruct the flow and sediment deposition processes in the channel and on the floodplain [15]. This paper anticipates a few significant results of the ongoing experimental efforts.

\section{Results and Discussion}

All experimental results in this paper are illustrated in prototype dimensions. Moreover, due to the different width of the wall elements, the impact forces are described as the normal component of the force vector per unit width $\left[\mathrm{kN} \mathrm{m}^{-1}\right]$ to describe them independently from the wall width and make the values better comparable with each other.

As observed in different studies for clear water conditions $[1,5,8,10]$, the impact forces are highly depending on the flow behaviour around the obstacle in the flow, which is mostly depending on the Froude number of the flow and the width of the obstacle. Accordingly, Riviere et al. [10] for example defined two different approaching flow patterns for clear water conditions, a detached hydraulic jump and a wall-jet-like bow wave. This could also be observed in the preliminary experiments of the presented studies, when varying the longitudinal gradient of the flume and the width of the wall element, which directly influence the flow velocities and the Froude number of the approaching flow [13].

When sediment transport is considered, different mechanisms can be observed. The preliminary experiments showed that sediments in the flow mixture do not necessarily increase the impact forces. At lower flow velocities, the sediments do not even touch the wall, because of the deceleration in the backwater of the plate. The deposition of the sediments in front of the plate further leads to deflections of the flow and shields the wall elements. This results in a decrease of the impact forces due to sediment supply (Fig. 2a). When considering a whole floodplain, the deposition processes should be regarded globally, not only focusing on single walls, which shows a high, random variability of the deposition processes on the floodplain. Flow paths are developed at the deposited sediments, which canalize the flow and force it randomly to different directions (Fig. 2b). This leads to temporally changing impact forces, depending on the different sediment depositions and the developed flow paths on the floodplain.

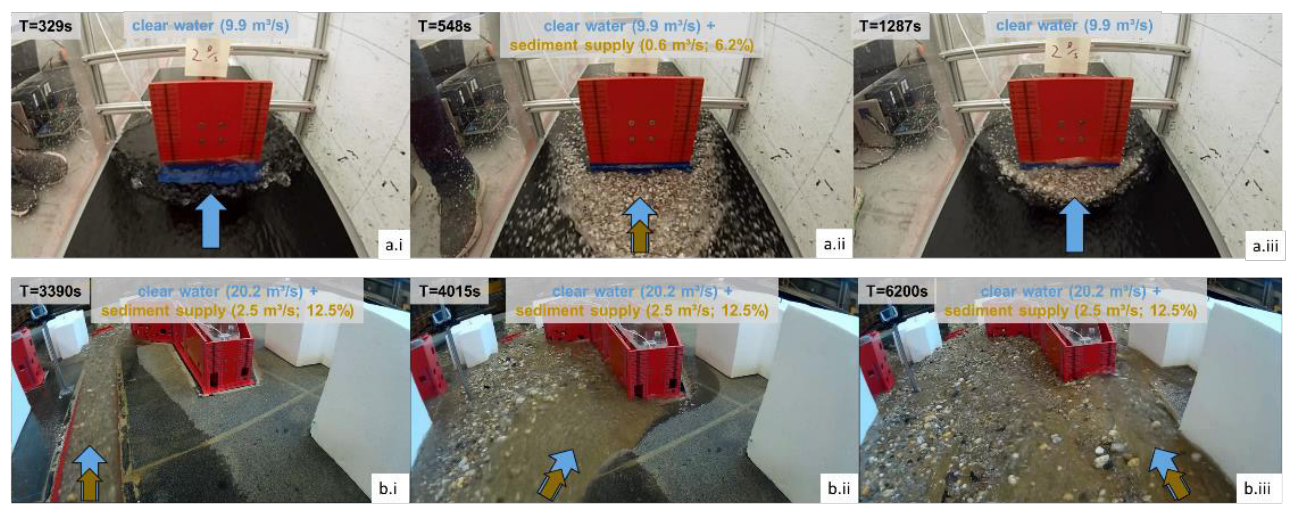

Fig. 2. a) Deflection of the flow through sediment deposition, single wall element, preliminary experiments; b) Canalizing of the flow through sediment deposition, whole building structures, Schnannerbach experiments; prototype dimensions (1:30, Froude).

Even though the preliminary experiments showed a decrease of the impact forces due to sediment supply on a single wall element, the scale model experiments of the Schnannerbach Torrent also highlighted that the depositions could lead to an increase of the flow impacts. Fig. 2 shows both experimental setups at different times of an experiment under sediment- 
loaded conditions. Here, the sediment depositions lead to variable approaching flow heights on the walls which directly influence the impact forces (Fig. 3).

Fig. 3 shows the correlation of the approaching flow height and the specific impact force. The measurements were classified in all measurements of the 120 clear water experiments and in all measurements of the 20 sediment transport experiments. The clear water experiments provide steady state conditions on the whole floodplain and present mean values. Because of the ongoing temporal fluctuations of the sediment depositions on the floodplain even at steady-state boundary conditions, the displayed forces and associated approaching flow heights of the sediment transport experiments present time-averaged mean values over defined durations during the experiments. Further, the clear water measurements of the preliminary studies are added to the diagram. The experiments show good correlation of the approaching flow heights and the specific normal forces for clear water conditions. The values of the sediment transport experiments are much more scattered and even large impact forces could be measured at low flow heights. A quadric regression curve was generated for each set of measurements. Both clear water measurements of the two different scale models fit very well together with a broader fluctuation of the impact forces at higher approaching flow heights. Nevertheless, even if the sediment experiments provide a much higher fluctuation of the measurements, the three illustrated regression curves match pretty well.

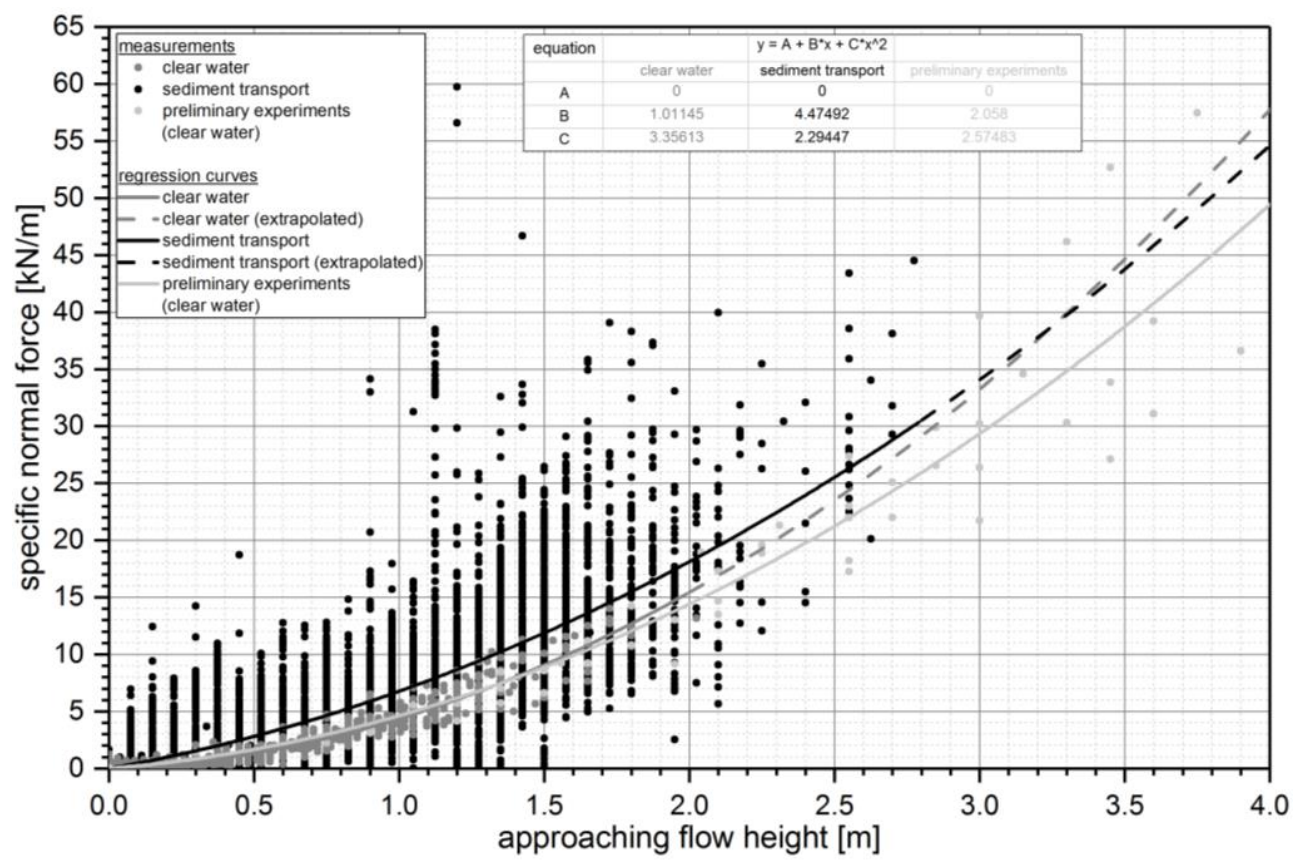

Fig. 3. Correlation of approaching flow height and specific normal force for different experimental sets; prototype dimensions (1:30, Froude).

The comparison of the maximum impact forces of the two different model layouts with and without surrounding buildings shows either equal, increasing or decreasing impact forces for the three specific buildings, also underlying the spread of the measured values. In Fig. 4 the maximum forces of the corresponding experiments with sediment transport were compared with each other individually for the three buildings and the 16 measurement devices. The line in the diagrams marks the equality of the two model layouts. Building 1 shows a consistent distribution of the measurements on both sides of the line for most of the six wall elements. When comparing the values to the sketch in Fig. 1, the close location of building 1 to the torrent channel leads to almost no influence on the impact forces of the 
surrounding buildings located further away. Only the building located upstream of building 1 slightly deflects the flow and forces more discharge to hit wall 2, which can clearly be identified in Fig. 4. When comparing the maximum impact forces of building 2, most of the values are larger for the model layout with surrounding buildings. The building located upstream of building 2 forces almost the whole discharge of the orographic right side of the river to building 2 which increases the impact forces significantly (Fig. 2b.iii). Building 3 also shows a spread of the values. The buildings located between building 1 and 3 deflect the flow and shield wall element 13. The impact forces for wall 13 are, therefore, lower at the model layout with surrounding buildings. Wall elements 14 and 15 are almost unaffected by the influence of surrounding buildings.

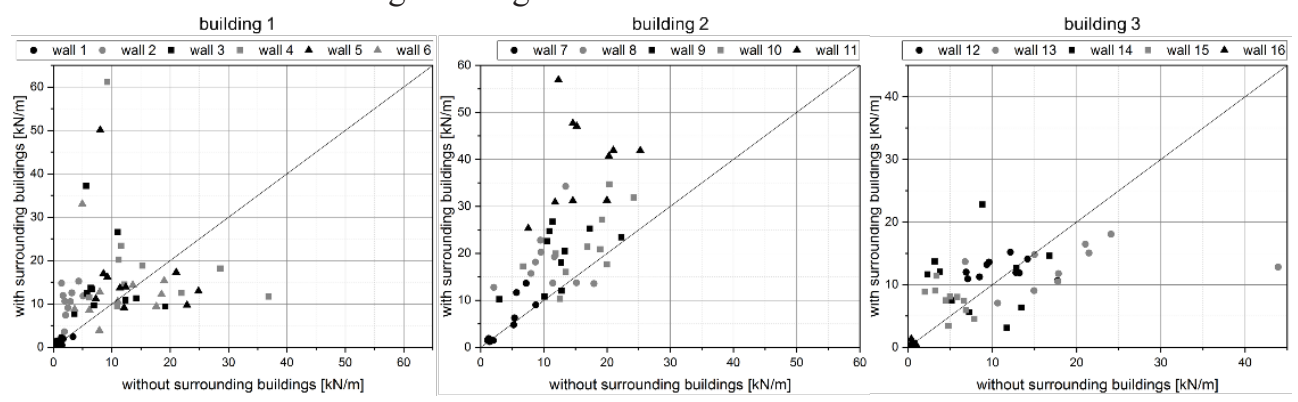

Fig. 4. Comparison of the influence of surrounding buildings on the maximum impact forces for three different buildings on the alluvial fan; Schnannerbach experiments; prototype dimensions (1:30, Froude).

As the results show, the impact forces can clearly be correlated to the approaching flow heights. The influence of obstacles around the three buildings on the impact forces can clearly be demonstrated by the experiments. The sediment deposition patterns in front of the buildings as well as the randomly developed depositions on the floodplain are mainly influencing the impact forces. Impacts of single boulders on the buildings could not be detected within these experiments with fluviatile sediment transport, sediment concentrations up to $15.5 \%$ and a diameter of the largest grain class of $96 \mathrm{~cm}$ (prototype dimensions) [15, $16]$.

\section{Conclusions}

The illustrated experiments introduce measurements of fluvial flood processes impacting on buildings. The measurements show the possible ranges and mean values of impact forces, both, for clear water and sediment loaded flow conditions. Correlations between the approaching flow heights and the impact forces are demonstrated, which follow quadratic regressions, depending on the existence of transported sediments in the flow. Experiments with water and sediment showed that the impacts on the walls are influenced by the sediment deposition process on the floodplain. Adjacent objects such as surrounding buildings, which can also be compared to local protection measures, highly influence the measured forces. In this context, the results should be considered in the planning of local protection measures for specific objects due to possible negative effects on objects located further downstream. Furthermore, the mutual influence of buildings on the flow processes should be considered in land use planning and hazard zone mapping in order to further reduce the flood risk and possible damages. Even though it is not necessarily expected that the impact forces of fluviatile sediment transport processes cause any structural damage on the buildings in terms of stress and stability analyses, the approaching flow heights and the correlating impact forces should be kept as low as possible for flood protection. 
The results of the study may be relevant and beneficial for other analyses such as structural analysis, the evaluation of the stability, bearing capacity and serviceability of buildings. Moreover, these findings can further support and improve vulnerability analysis for disaster risk reduction [7]. The measurements of the impact forces provide additional data to support the use of indicators for loss estimations employed in vulnerability analyses. Usually, most of the datasets used in vulnerability analyses are recorded after the flood event, as for example the sediment deposition heights. The flow processes during the flood event can only be qualitatively estimated based on sporadically available observations, photos, etc. By use of the experiments, it is possible to get a picture of how the natural process evolves in time and to get some real time data for specific locations on the field.

Scale model experiments provide detailed information and accurate measurements in the course of case studies. However, they underlie certain assumptions and model laws and require considerable efforts. Furthermore, numerical analyses underlie assumptions and simplifications as well. Moreover, they require important measurement data for model calibration and validation. The case study of the Schnannerbach delivers experimental data on specific experimental settings which can be used for calibration of numerical models [15]. The settings of the most relevant calibration parameters can be applied also for further numerical investigations on other, with regard to the catchment and process characteristics comparable, case studies.

The study originates from the project "Vulnerability analysis of buildings exposed to torrent hazards small scale experimental modelling of impacts on buildings and derivation of physics-based vulnerability functions", funded by the Austrian Science Fund (FWF: P27400-NBL). Bruno Mazzorana has also been supported by the Iniciativa Cientifica Milenio (ICM) through grant NC160025 "Millenium Nucleus CYCLO - The Seismic Cycle Along Subduction Zones". Maria Papathoma-Köhle has also been supported by the FWF-Elise Richter-programme for the project "Physical vulnerability assessment using indicators. A methodological framework" (Austrian Science Fund (FWF): V-519N29).

\section{References}

1. Armanini, A., Larcher, M., and Odorizzi, M.: Dynamic impact of steep waves against a vertical wall. Proceedings of First European IAHR Congress, Edinburgh, (2010)

2. Chiari, M.: Numerical modelling of bedload transport in torrents and mountain streams. PhD thesis, University of Natural Resources and Life Sciences, Vienna, (2008)

3. Gems, B., Sturm, M., Vogl, A., Weber, C., and Aufleger, M.: Analysis of damage causing hazard processes on a torrent fan - scale model tests of the Schnannerbach Torrent channel and its entry to the receiving water. Digital Proceedings of the Interpraevent in the Pacific Rim, Nara, (2014)

4. Göttgens, H.: Experimentelle Untersuchung zur Einwirkung geschiebeführender Abflüsse auf Gebäude. Master thesis, University of Innsbruck, (2016) (in German)

5. Guillen-Ludena, S., Lopez, D., Riviere, N., and Mignot, E.: Extreme flood flow in an increasingly urbanized floodplain: an experimental approach. Proceedings of the 37th IAHR World Congress, Kuala Lumpur, (2017)

6. Keller, F.: Physikalische Modellversuche zur Ermittlung der Belastung auf Gebäude infolge geschiebeführender Hochwasserereignisse. Master thesis, University of Innsbruck, (2017) (in German)

7. Mazzorana, B., Simoni, S., Scherer, C., Gems, B., Fuchs, S., and Keiler, M.: A physical approach on flood risk vulnerability of buildings. Hydrol. Earth Syst. Sc., 18 (9), 3817 3836, doi: 10.5194/hess-18-3817-2014, (2014) 
8. Mignot, E. and Riviere, N.: Bow-wave-like hydraulic jump and horseshoe vortex around an obstacle in a supercritical open channel flow, Phys. Fluids. 22, 117105, (2010)

9. Papathoma-Köhle, M., Gems, B., Sturm, M., and Fuchs, S.: Matrices, curves and indicators: A review of approaches to assess physical vulnerability to debris flows. Earth-Sci. Rev. 171, 272-288, https://doi.org/10.1016/j.earscirev.2017.06.007, (2017)

10. Riviere, N., Vouaillat, G., Launay, G., and Mignot, E.: Emerging obstacles in Supercritical Open-Channel Flows: Detached Hydraulic Jump versus Wall-Jet-Like Bow Wave. J. Hydraul. Eng. 143 (7), (2017)

11. Rudolf-Miklau F., Ellmer, A., Gruber, H., Hübl, J., Kleemayr, K., Lang, E., Markart, G., Scheuringer, E., Schmid, F., Schnetzer, I., Weber, C., and Wöhrer-Alge, M.: Hochwasser 2005 - Ereignisdokumentation, Teilbericht der Wildbach- und Lawinenverbauung, Vienna, (2006) (in German)

12. Scheidl, C., Chiari, M., Kaitna, R., Müllegger, M., Krawtschuk, A., Zimmermann, T., and Proske, D.: Analysing Debris-Flow Impact Models, Based on a Small Scale Modelling Approach. Surv. Geophys. 34, 121-140, (2013)

13. Sturm, M., Gems B., Aufleger M., Mazzorana B., Papathoma-Köhle M., and Fuchs S.: Scale model measurements of impact forces on obstacles induced by bed-load transport processes. Proceedings of the 37th IAHR World Congress, Kuala Lumpur, (2017a)

14. Sturm, M., Gems B., Mazzorana B., Gabl R., and Aufleger M.: Validierung experimenteller und 3-D-numerischer Untersuchungen zur Einwirkung hydrodynamischer Fließprozesse auf Objekte. WasserWirtschaft, 06/2017, 21-27, (2017b) (in German)

15. Sturm, M., Gems, B., Keller, F., Mazzorana, B., Fuchs, S., Papathoma-Köhle, M. and Aufleger, M.: Impact forces on buildings exposed to fluvial hazards. In Review for Journal of Hydrology

16. Sturm, M., Gems, B., Keller, F., Mazzorana, B., Fuchs, S., Papathoma-Köhle, M. and Aufleger, M.: Factors with major influence on impact forces at buildings caused by fluviatile sediment transport processes (to be published)

17. Totschnig, R., Sedlacek, W., and Fuchs, S.: A quantitative vulnerability function for fluvial sediment transport. Eng. Geol. 58, 681-703, doi: 10.1007/s11069-010-9623-5, (2011) 